\title{
Development of Adsorbent from Phytoremediation Plant Waste for Methylene Blue Removal
}

\author{
Atyaf Farooq Alshekhli, Hassimi Abu Hasan 1*, Mohd Hafizuddin Muhamad', \\ Siti Rozaimah Sheikh Abdullah' \\ 1 Department of Chemical and Process Engineering, Faculty of Engineering and Built Environment, Universiti \\ Kebangsaan Malaysia, 43600 UKM Bangi, Selangor, Malaysia \\ * Corresponding author's e-mail: hassimi@ukm.edu.my
}

\begin{abstract}
Dyes are considered to be hazardous, have low biodegradability and can affect the human health as well as the aquatic life cycle. This research investigated the methylene blue (MB) removal using an activated carbon matrix of Scirpus grouss (waste that was initially used for phytoremediation of soil). The experiment was conducted in a flask containing $0.5 \mathrm{~g} \mathrm{AC-SC}$ with MB concentrations of 5 and $15 \mathrm{mg} / \mathrm{L}$. The adsorption was monitored for $120 \mathrm{sec}$. The results showed complete removal of MB within a contact time of $30 \mathrm{sec}$ using 6-AC. The surface morphology analysis showed that at 6-AC, the structure was more porous. The ultimate potential of activated carbon prepared from the phytoremediation plant waste would be the best alternative for the water and wastewater treatment, while it provides an alternative to the phytoremediation waste management process.
\end{abstract}

Keywords: Methylene blue; dye removal; activated carbon; Scirpus grossus; phytoremediation

\section{INTRODUCTION}

There is an increasing trend of various industries using different dyes, leading to the accumulation of toxic pollutants in the environment. Dyes are considered to be dangerous pollutants and are released to the environment in large quantities from the textile, paper and pulp, tannery, and paint industries (Gupta \& Suhas 2009; Muhamad et al. 2015). They are considered to be hazardous, have low biodegradability, and can affect the human health as well as the aquatic life cycle. Due to its wide usage in the textile industries for dyeing leather, cotton, printing, and tanning, methylene blue (MB) is one of the basic (cationic) dyes that is often found in the dye-based industrial wastewater (Gupta et al. 2004). Methylene blue has can have serious effects when consumed by humans; it can cause confusion, shortness of breath, vomiting, high blood pressure, many allergic reactions, and cancer.

Many studies have been conducted to examine various methods for the MB removal such as electrocoagulation (Golder et al. 2005; Mahmoud et al. 2013), ozonation (Al-Jibouri et al. 2015), electrolysis (Liu et al. 2020; Zhang et al. 2013), phytoremediation (Almaamary et al. 2017; Al-Badawi et al. 2018), photocatalyst (Kumar et al. 2002; Ahmed et al. 2016) and adsorption (Jawad et al. 2019; Somsesta et al. 2020; Sulizi et al. 2020). Several of these methods are expensive and have low removal efficiency. Moreover, physical-chemical methods are not effective for dye removal due to the low biodegradability of the dye itself. Some studies utilised clays, fly ash, activated carbon, and hydrogel for the dye removal (Bouatay et al. 2015; Basava Rao \& Ram Mohan Rao 2006; Ahmad et al. 2020). Alternatively, phytoremediation is a process that uses different kinds of plants to remove contaminants, for example, a study conducted by Imron et al. (2019) showed successful phytoremediation of MB using duckweed (Lemna minor).

In general, plants consist of cellulose, hemicellulose, and pectin; they have different functional groups such as hydroxyl, carboxyl, and 
carbonyl. This is beneficial because the functional groups of these plants interact well with the functional groups of dyes, leading to the binding of dyes to the biomass of the plants. Many studies demonstrated the tremendous potential of the Scirpus grossus plant for the removal of MB from the textile wastewater. The $S$. grossus plant is a plant which is extremely efficient at contaminant removal (Tangahu et al. 2019). It is also considered to be a less expensive source of biomass, although no suggestions regarding the disposal of the plant waste after it has been used in phytoremediation have been made.

This study investigates the possibilities for handling the phytoremediation plant waste and attempts to fabricate a novel biofilm carrier from the phytoremediation waste and cement to enhance the dye removal from industrial wastewater. The grossus plant waste was used in this research to be tested on the MB decolourisation.

\section{METHODOLOGY}

\section{Plant collection}

The $S$. grossus plant waste was collected from the greenhouses located in the Universiti Kebangsaan Malaysia (UKM). The plant waste was washed thoroughly with tap water to remove the dirt and was then cut into small pieces measuring $0.5 \mathrm{~cm}$ using scissors. The plant material was then dried for three days under the Sun. Lastly, the small pieces were washed three times with distilled water, spread into two aluminium foil trays and dried inside an oven (Protech, Model FAC-350, Malaysia) at $110^{\circ} \mathrm{C}$ for $24 \mathrm{hr}$. The dried plant material was stored in a sealed container for further use.

\section{Impregnation process}

The adsorbent was prepared using a modified chemical activation method as described by Collin et al. (2015). The dried plant waste (25 g) was impregnated with phosphoric acid $\left(\mathrm{H}_{3} \mathrm{PO}_{4}\right)$ as a dehydrating agent at concentrations of $2 \mathrm{M}$ (2-AC), $4 \mathrm{M}$ (4-AC), and $6 \mathrm{M}$ (6-AC). Each impregnation was conducted in a $500 \mathrm{~mL}$ conical flask. The conical flasks were covered with cotton wool, sealed with laboratory film, and transferred to a water bath at $80^{\circ} \mathrm{C}$ for three days. The samples were shaken manually from time to time to ensure the plant material absorbed the reagent. After three days, the samples were transferred to a Petri dish and dried inside an oven at $110{ }^{\circ} \mathrm{C}$ for $24 \mathrm{hr}$. The samples were then cooled in a clean crucible covered with a lid and kept in a sealed container for the activation process.

\section{Activation process}

A two-step activation process was achieved using a muffle furnace. The samples were semicarbonised at $200^{\circ} \mathrm{C}$ for $15 \mathrm{~min}$. The furnace temperature was then adjusted to the desired activation temperature of $500^{\circ} \mathrm{C}$ and activated for 45 min. Lastly, the chemical S. grossus activated carbon (AC) was washed several times with distilled water to remove the residual acid from the adsorbent surface to obtain the final adsorbent.

\section{AC matrix preparation}

The $S$. grossus AC was mixed with cement to fabricate a heavier adsorbent to be used for the MB removal. Initially, AC was ground into powder using a mortar and was then mixed with cement powder at a fixed ratio of 1:1 for each type of $\mathrm{AC}$ at different impregnation concentrations. After mixing the cement with $\mathrm{AC}$, approximately $2 \mathrm{~mL}$ of distilled water was added, the solution was mixed and dried completely under the sunlight. The AC matrices were crushed into small granules before being used for the MB adsorption.

\section{Methylene blue adsorption}

A stock solution of MB was prepared by dissolving MB (5 and $15 \mathrm{mg}$ ) in 1 litre of distilled water. The adsorption was conducted using a $50 \mathrm{~mL}$ conical flask. Approximately $15 \mathrm{~mL}$ of $5 \mathrm{mg} / \mathrm{L}$ and $15 \mathrm{mg} / \mathrm{L} \mathrm{MB}$ solution were poured into the flask and then $0.5 \mathrm{~g}$ of the AC matrix was added to the solution. The flask was shaken at $50 \mathrm{rpm}$ and $25^{\circ} \mathrm{C}$ for a variety of contact times $(10,20$, 30,60 and $120 \mathrm{sec}$ ). After the desired contact time was achieved, each solution was centrifuged for $15 \mathrm{~min}$ at $3000 \mathrm{rpm}$ and the supernatants were filtered using a $0.45 \mu \mathrm{m}$ syringe filter before being tested for the final concentration of MB using a UV spectrophotometer (HACH DR6000) at a wavelength of $665 \mathrm{~nm}$. 


\section{AC Characterisation}

The surface structure of $S$. grossus AC (SG-AC) was observed under field-emission scanning electron microscopy (FESEM), while the chemical elements were determined using energy dispersive $\mathrm{x}$-ray (EDX). Chemical functional groups of $\mathrm{AC}$ were analysed using Fourier transform infrared spectroscopy (FTIR). This technique measures the sample absorption capability of infrared radiation versus wavelength.

\section{RESULTS AND DISCUSSION}

\section{Surface structure analysis}

FESEM analysis was performed to determine the physical characteristics of $\mathrm{AC}$, in order to analyse the surface morphology. Figure 1 illustrates the FESEM imaging of AC at various impregnation concentrations. It was obvious from the results that increasing the $\mathrm{H}_{3} \mathrm{PO}_{4}$ concentrations increased the hexagonal layer size due to the agglomeration of the carbon particles. Thus, the treatment of $\mathrm{H}_{3} \mathrm{PO}_{4}$ could promote the bond cleavage reactions and the $\mathrm{H}_{2} \mathrm{PO}^{4-}$ ions forming a hydrogen bond network with carbon through the Grotthuss mechanism (Abdulkreem-Alsultan et al. 2016). The chemical element composition of AC is shown in Figure 2. All EDX spectrums indicated the presence of peaks that corresponded to $\mathrm{C}, \mathrm{O}, \mathrm{P}$ and $\mathrm{Si}$. The existence of $\mathrm{P}$ species confirms the successful phosphonation of activated carbon with $\mathrm{H}_{3} \mathrm{PO}_{4}$.

\section{Chemical functional groups}

Fourier transform infrared spectroscopy (FTIR) is a vibrational spectroscopy technique that provides distinct adsorption peaks which can be identified and apportioned to specific chemical bonds to qualitatively or quantitatively identify the functional groups present in a multifaceted sample. As shown in Figure 3, AC demonstrated a distinct broad peak from $3449 \mathrm{~cm}^{-1}$ region which refers to the stretching of the carboxylic acid O-H group. The AC absorption band was normalised by the intensity of the absorption band centred around $1578 \mathrm{~cm}^{-1}$, attributed to $\mathrm{C}=\mathrm{C}$ or the aromatic ring in the wood (De Mattos et al. 2012). All the samples were found to have absorption peaks at $1411 \mathrm{~cm}^{-1}(\mathrm{C}=\mathrm{C}), 1000 \mathrm{~cm}^{-1}(\mathrm{P}=\mathrm{O})$, $692 \mathrm{~cm}^{-1}$ (C-C stretching) and 492 and $478 \mathrm{~cm}^{-1}$ (C-C bending). The disappearance of absorption band intensity at $3405 \mathrm{~cm}^{-1}(\mathrm{C}-\mathrm{H})$ stretching vibration for $\mathrm{AC}$ when the $\mathrm{H}_{3} \mathrm{PO}_{4}$ was $6 \mathrm{M}$ indicated that the activation step successfully removed a significant amount of hydrogen after activation in the form of hydrogen gas (Heidari et al. 2014). The presence of a phosphate group was confirmed by clear and strong vibration bands at $1001 \mathrm{~cm}^{-1}$ assigned to the $\mathrm{P}=\mathrm{O}$ stretching vibrations of the $\mathrm{HPO}_{4}^{2-}$ units, proving the presence of the $-\mathrm{PO}_{3} \mathrm{H}$ group covalently bonded to the polyaromatic carbon structure. The absence of $\mathrm{C}=\mathrm{O}$ at absorption band $1615 \mathrm{~cm}^{-1}$ in $\mathrm{AC}$ indicated that the chemical activation broken between carbon and oxygen bonds in the aliphatic and aromatic species simultaneously eliminated many $\mathrm{C}=\mathrm{O}$ from the parent material (Hesas et al. 2013). Increasing the $\mathrm{H}_{3} \mathrm{PO}_{4}$ concentrations from 0 to $6 \mathrm{M}$ resulted in an increase in the absorption band intensity at $1553 \mathrm{~cm}^{-1}(\mathrm{C}=\mathrm{C})$ and $545 \mathrm{~cm}^{-1}(\mathrm{C}-\mathrm{C})$. This was due to the interaction between the phosphate groups and the carbon (De Mattos et al. 2012; Bi $\& \mathrm{He}, 2013)$.

\section{Physical observation}

Adsorption of $\mathrm{MB}$ onto different $\mathrm{AC}$ matrices was investigated at time intervals of $0,10,20,30$, 60 and $120 \mathrm{sec}$ with the concentrations of 5 and $15 \mathrm{mg} / \mathrm{L}$ of MB. As shown in Figure 4, for $5 \mathrm{mg} / \mathrm{L}$ of $\mathrm{MB}$, the adsorption increased for the $\mathrm{AC}$ that was subjected to the impregnation process with $\mathrm{H}_{3} \mathrm{PO}_{4}$ at concentrations of 2,4 , and $6 \mathrm{M}$ in comparison with the $\mathrm{AC}$ without impregnation.

\section{Adsorption of MB}

Figure 5(a) illustrates the results of the MB removal by the $S$. grossus AC matrix. The C-AC removed $\mathrm{MB}$ in $97-99 \%$ after contact times ranging from 10 to $30 \mathrm{sec}$. At $60 \mathrm{sec}, \mathrm{MB}$ was completely adsorbed onto the C-AC. The impregnation concentrations appeared to play a key role in the development of the morphology of the adsorbents which showed an excellent result by completely adsorbing MB after a contact time of $30 \mathrm{sec}$ (2-AC, 4-AC and 6-AC). This explained the high porosity and surface area of the AC. During a comparison of the adsorbents, it was observed that the $\mathrm{C}-\mathrm{AC}$ required more contact time. 

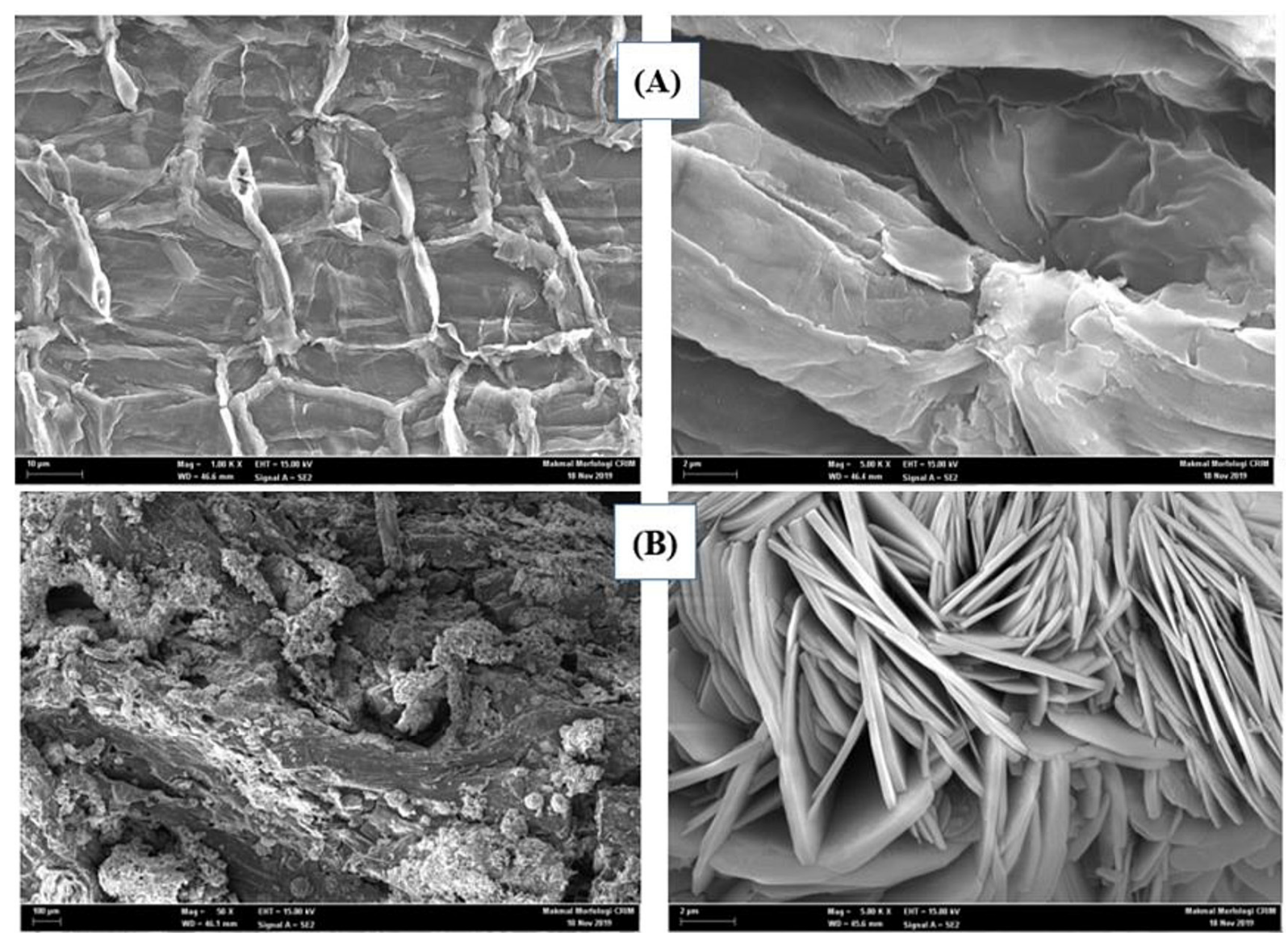

(B)
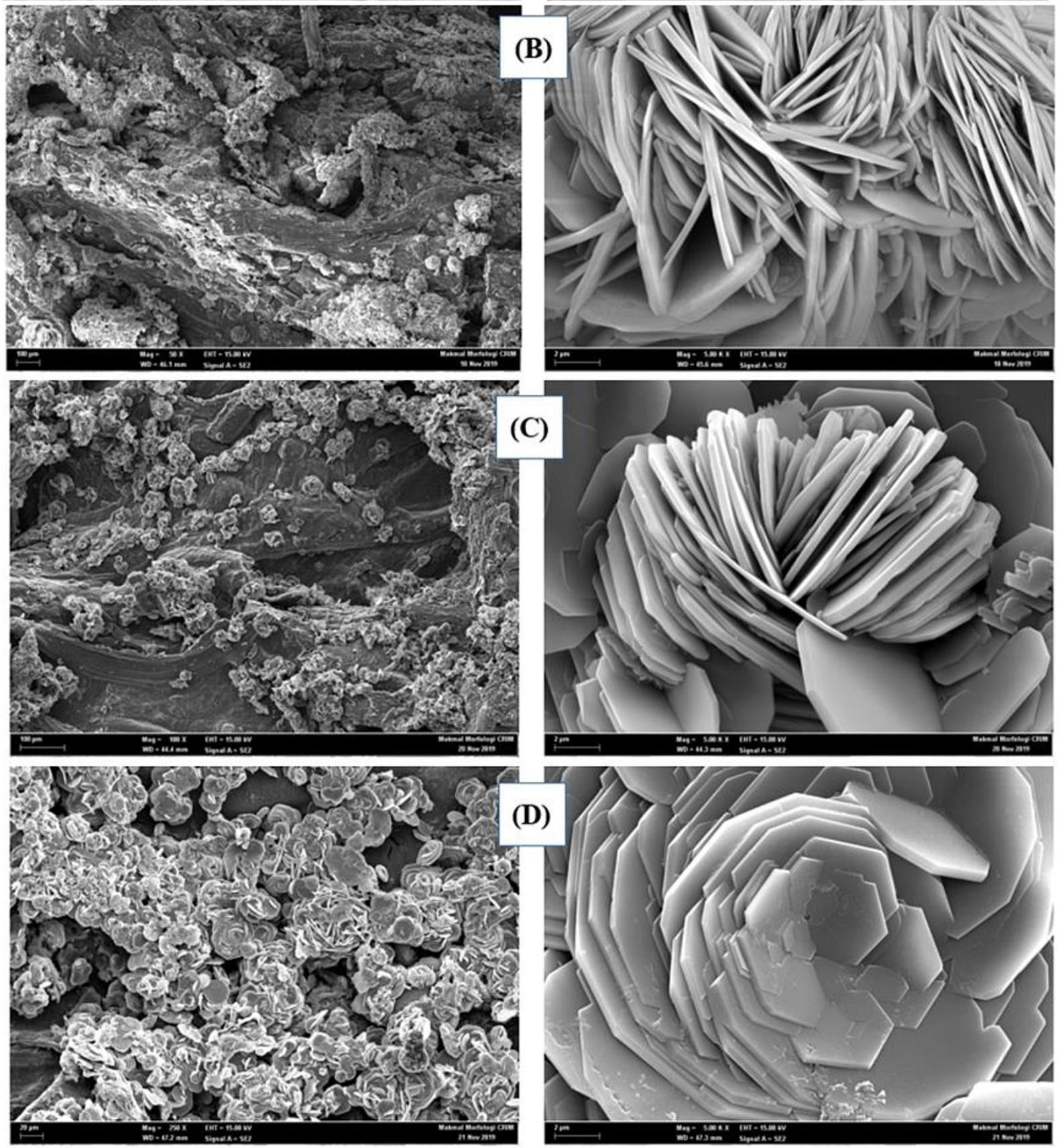

Figure 1. Surface structure of AC after impregnation with $\mathrm{H}_{3} \mathrm{PO}_{4}$ (a) control, (b) $2 \mathrm{M}$, (c) 4M, and (d) $6 \mathrm{M}$ of $\mathrm{H}_{3} \mathrm{PO}_{4}$ without the addition of cement 

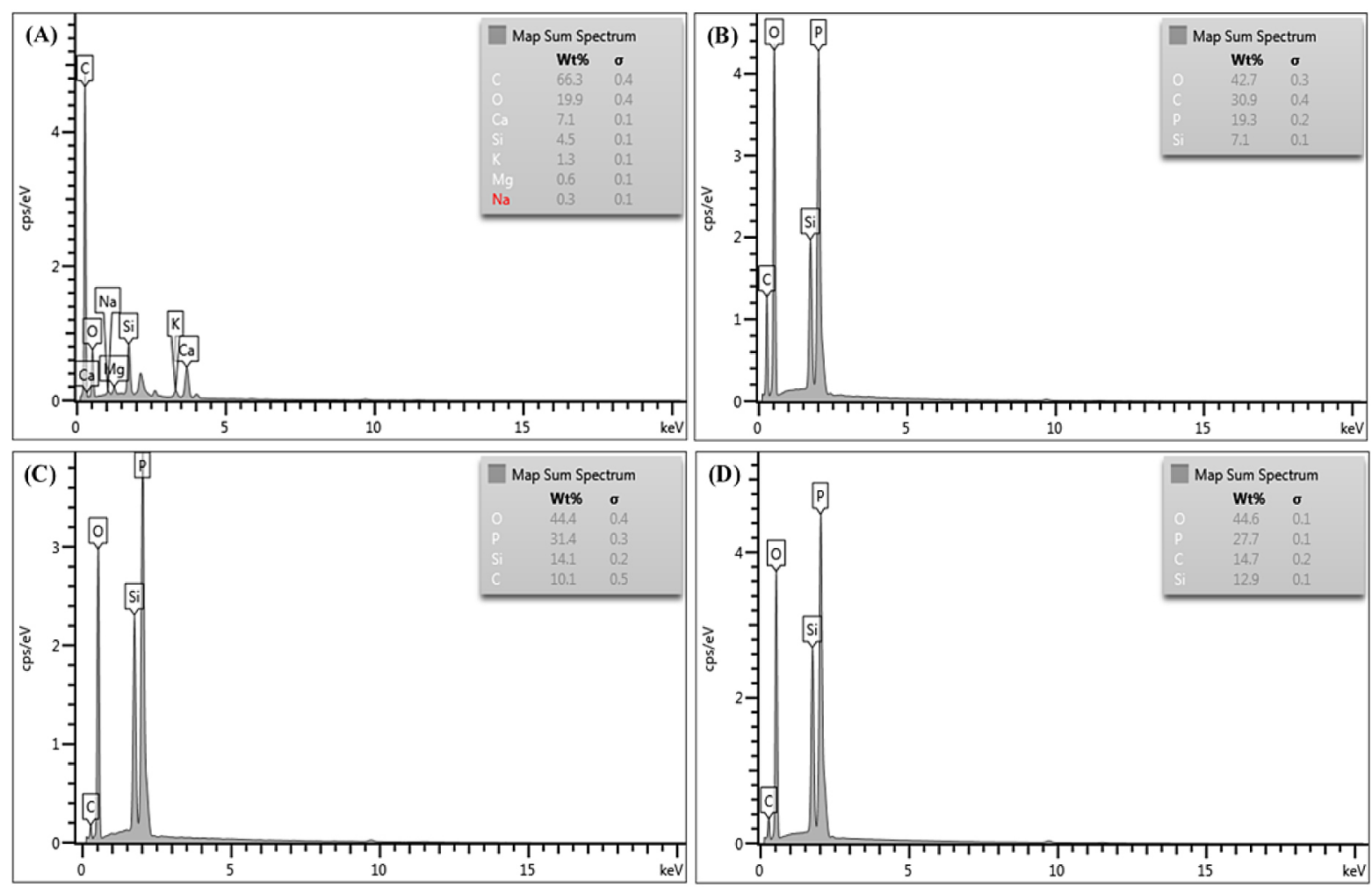

Figure 2. EDX results after impregnation with $\mathrm{H}_{3} \mathrm{PO}_{4}$ (a) control, (b) 2-AC, (c) 4-AC, and (d) 6-AC

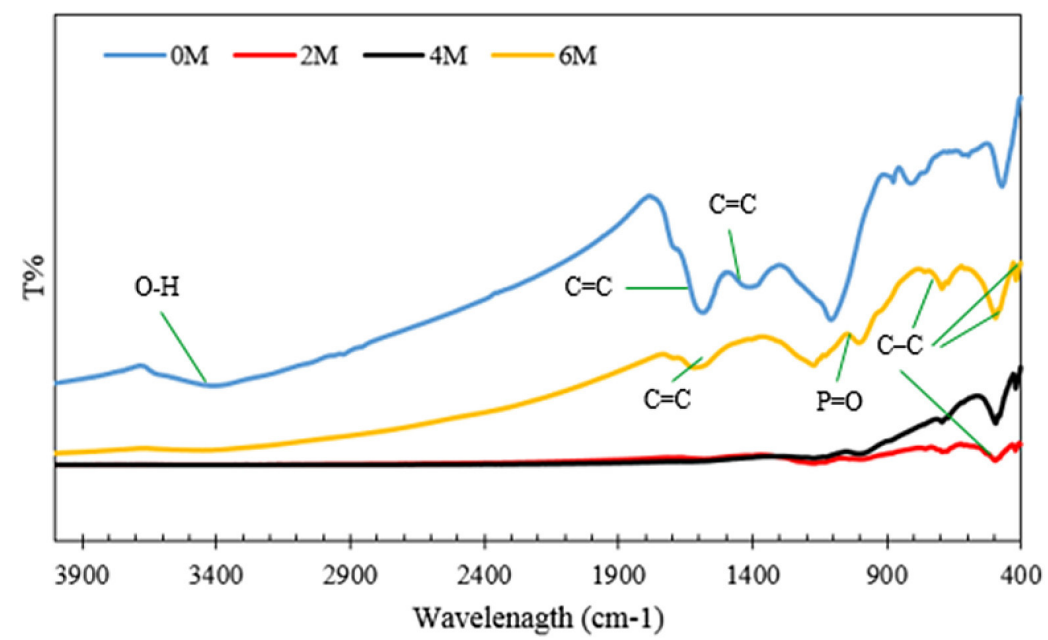

Figure 3. FTIR profile of prepared AC

The impregnation process and addition of cement appeared to influence the development of a porous structure and increased the surface area of $\mathrm{AC}$, as confirmed by the FESEM results (Figure 6).

The adsorbents prepared without the addition of cement were also tested for the MB removal. The results showed a complete MB removal after a contact time ranging from 3 to $5 \mathrm{~min}$. This finding showed that the addition of cement significantly enhanced the performance of the adsorbent, as it increased the porosity, consequently enhancing the adsorption of MB in shorter time. The efficiency of the $15 \mathrm{mg} / \mathrm{L} \mathrm{MB}$ solution is illustrated in Figure 5(b). It was found that 4-AC and 6-AC were the most effective adsorbents as they almost completely removed MB in less than $60 \mathrm{sec}$ compared to other AC. At $60 \mathrm{sec}$, the MB concentrations were measured at 1.2, 0.6, 0.005, and $0.001 \mathrm{mg} / \mathrm{L}$ for $\mathrm{C}-\mathrm{AC}, 2-\mathrm{AC}, 4-\mathrm{AC}$, and $6-\mathrm{AC}$, respectively. 

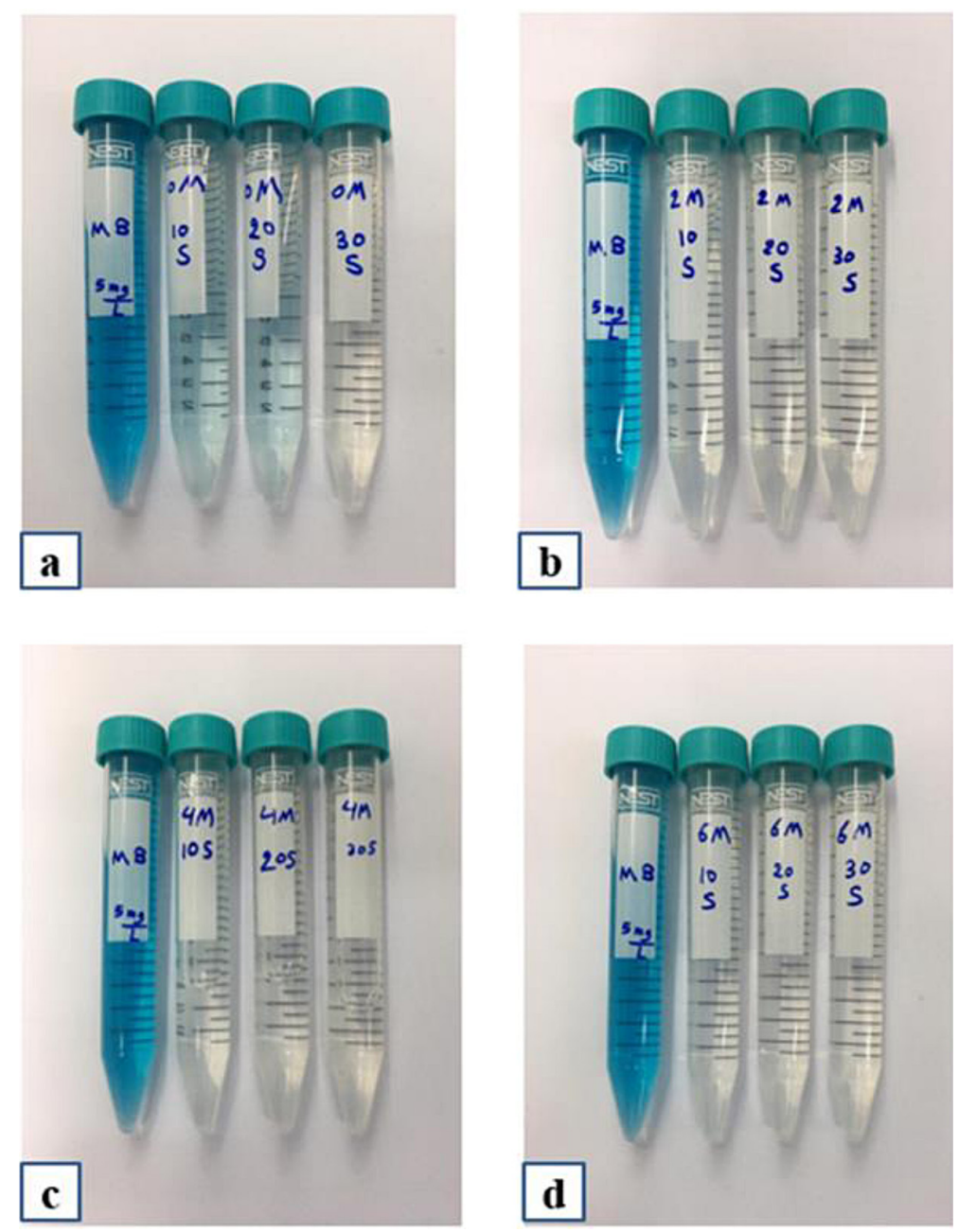

Figure 4 Observation of MB colour reduction for (a) C-AC, (b) 2-AC, (c) 4-AC, and (d) 6-AC

\section{Comparison with other studies}

The previous studies reported various types of adsorbent for MB removal such as corn husk, mango leaf, coconut shell, Fava bean peel, $F i$ cus carica bast, and phytoremediation plantbased adsorbent such $S$. grossus as summarised in Table 1. Most studies utilised a synthetic MB solution at high concentrations $(>50 \mathrm{mg} / \mathrm{L})$, whereas there is a lack of studies which used low concentrations of MB. Bayomie et al. (2020) developed a novel adsorbent using fava bean peel to adsorb low concentrations of MB (3.6-25 mg/L). In the study, researchers observed that within $20 \mathrm{~min}, 0.5 \mathrm{~g}$ of fava bean peel could adsorb 70 to $80 \%$ of MB. In comparison, in this study, with an $\mathrm{MB}$ concentration of $15 \mathrm{mg} / \mathrm{L}$ and $0.5 \mathrm{~g}$ SG-AC, $100 \%$ removal was achieved in only 30 sec. Another study using corn husk AC achieved more than 95\% MB removal within $120 \mathrm{~min}$ under an acidic condition of $\mathrm{pH} 4$ (Khodaie et al. 2013). Similar findings were obtained in a study by Khodaie et al (2013) in which mango leaf adsorbent in powder form removed MB at an initial concentration of $100 \mathrm{mg} / \mathrm{L}$. However, in a study which used Ficus carica bast AC, the adsorption saturated after $60 \mathrm{~min}$ with removal at $60 \%$ (Pathania et al. 2017).

\section{CONCLUSION}

This study investigated the reuse of phytoremediation plant waste with the addition of cement as an adsorbent for the removal of MB in a solution. The tests showed that the adsorption of MB onto the adsorbent matrix was feasible and spontaneous due to the complete removal of MB within a short contact time of $30 \mathrm{sec}$. Moreover, the most effective impregnation was achieved at $6 \mathrm{M} \mathrm{H}_{3} \mathrm{PO}_{4}$. The analysis of characteristics showed that the adsorbent matrix at $6 \mathrm{M} \mathrm{H}_{3} \mathrm{PO}_{4}$ had a more porous structure. The findings indicated that phytoremediation plant waste could 


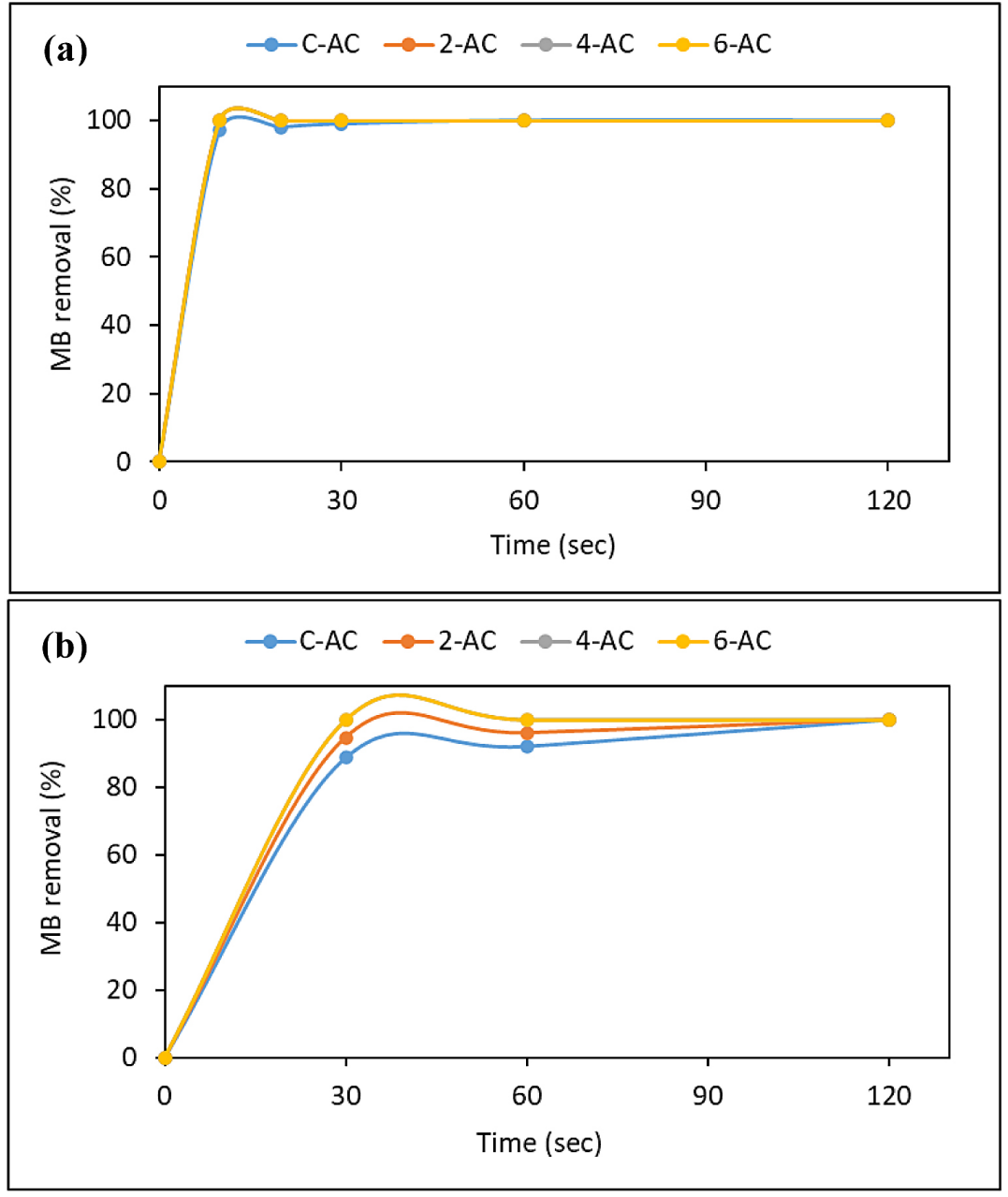

Figure 5. Removal of MB by AC based S. grossus (a) at $5 \mathrm{mg} / \mathrm{L} \mathrm{MB}$, and (b) at $15 \mathrm{mg} / \mathrm{L} \mathrm{MB}$
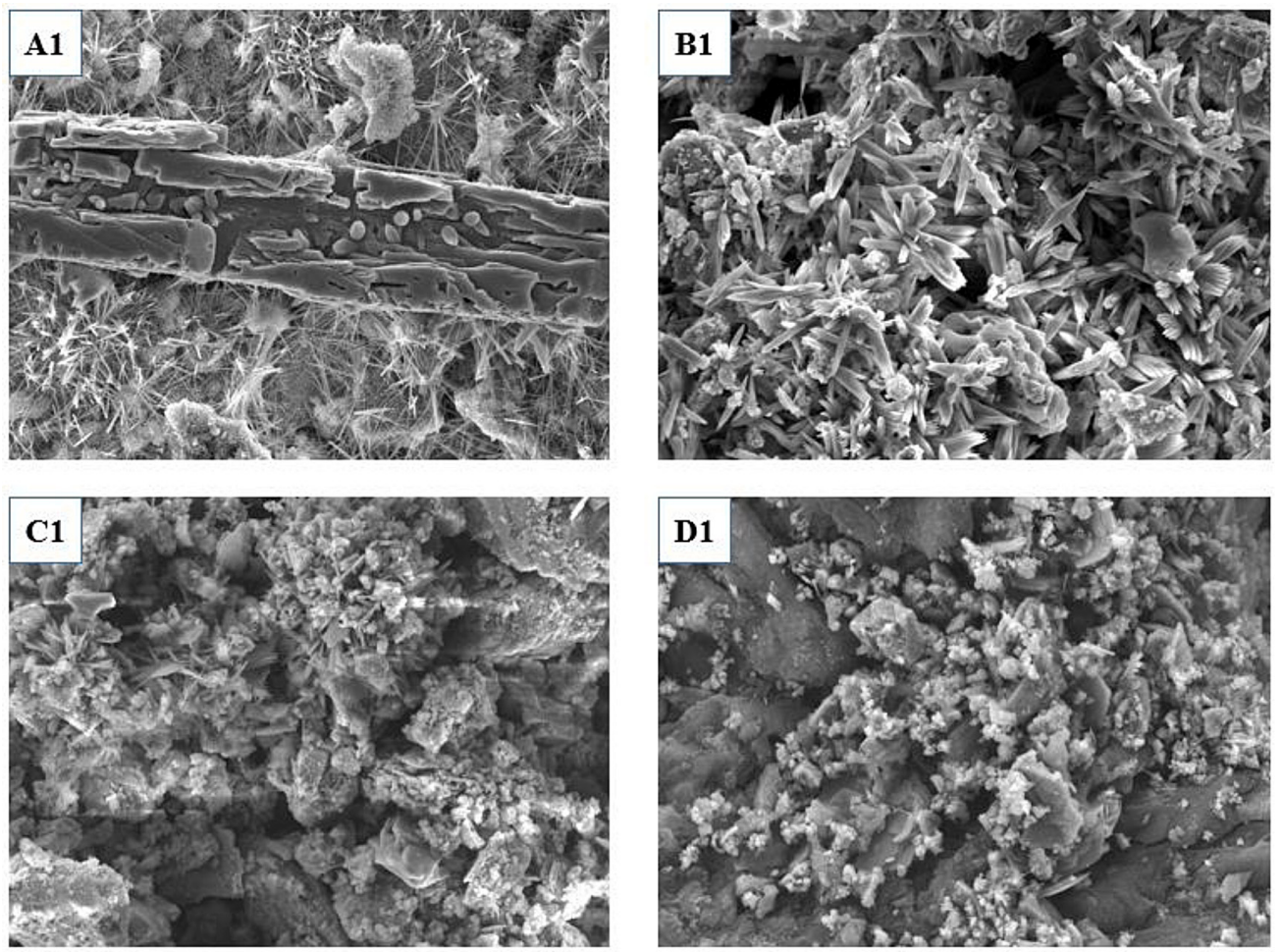

Figure 6. FESEM images of adsorbents after mixing with cement 
Table 1. Comparison of MB removal using various sources of AC

\begin{tabular}{|c|c|c|c|c|c|c|}
\hline $\begin{array}{l}\text { Type of activated } \\
\text { carbon }\end{array}$ & \begin{tabular}{|l|}
$\begin{array}{l}\text { Initial concentration } \\
(\mathrm{mg} / \mathrm{L})\end{array}$ \\
\end{tabular} & \begin{tabular}{|l|}
$\begin{array}{l}\text { Mass of } \\
\text { adsorbent }\end{array}$ \\
\end{tabular} & Time & $\mathrm{pH}$ & \begin{tabular}{|l|}
$\begin{array}{l}\text { Re moval } \\
(\%)\end{array}$ \\
\end{tabular} & References \\
\hline S. grossus & $15 \mathrm{mg} / \mathrm{L}$ & $0.5 \mathrm{~g}$ & $30 \mathrm{sec}$ & 6.0 & 100 & This study (2020) \\
\hline $\begin{array}{l}\text { Pea Shells } \\
\text { Pea Shells } \\
\text { Pea Shells } \\
\text { Pea shells }\end{array}$ & $250 \mathrm{mg} / \mathrm{L}$ & $0.5 \mathrm{~g}$ & $180 \min$ & 6.85 & 33.6 & Geçgel et al. (2013) \\
\hline Corn Husk & $50 \mathrm{mg} / \mathrm{L}$ & 0.5 & 120 & 4 & $>95$ & Khodaie et al. (2013) \\
\hline $\begin{array}{l}\text { Mango leaf } \\
\text { powder }\end{array}$ & 100 & 0.5 & 120 & - & $>95 \%$ & Uddin et al. (2017) \\
\hline $\begin{array}{l}\text { Typha orientalis } \\
\text { Typha orientalis } \\
\text { Typha orientalis } \\
\text { Typha orientalis } \\
\text { Ficus carica bast }\end{array}$ & 100 & 0.5 & 60 & 7.8 & $60 \%$ & Pathania et al. (2017) \\
\hline Coconut shell & 200 & 0.1 & 450 & 5.6 & $83 \%$ & Jawad et al. (2020) \\
\hline $\begin{array}{l}\text { Fava bean peel waste } \\
\text { Fava bean peel }\end{array}$ & $3.6-25 \mathrm{mg} / \mathrm{L}$ & 0.5 & 20 & 5.8 & $70-80 \%$ & Bayomie et al. (2020) \\
\hline
\end{tabular}

be processed to be reused as an adsorbent for the treatment of wastewater, thus creating a more sustainable process.

\section{Acknowledgement}

This research was financially supported by the Universiti Kebangsaan Malaysia with Grant No. DIP-2018-022.

\section{REFERENCES}

1. Abdulkreem-Alsultan, G., Islam, A., Janaun, J., Mastuli, M.S., Taufiq-Yap, Y.H. 2016. Synthesis of structured carbon nanorods for efficient hydrogen storage. Materials Letters, 17915, 57-60.

2. Ahmad, N.H., Mohamed, M.A., Yusoff, S.F.M. 2020. Improved adsorption performance of rubberbased hydrogel: optimisation through response surface methodology, isotherm, and kinetic studies. Journal of Sol-Gel Science and Technology, 94(2), 322-334.

3. Ahmed, Y., Yaakob, Z., Akhtar, P. 2016. Degradation and mineralization of methylene blue using a heterogeneous photo-Fenton catalyst under visible and solar light irradiation. Catalysis Science and Technology, 6(4), 1222-1232.

4. Al-Baldawi, I.A., Abdullah, S.R.S., Anuar, N., Hasan, H.A. 2018. Phytotransformation of methylene blue from water using aquatic plant (Azolla pinnata). Environmental Technology and Innovation ,11, 15-22.

5. Al-Jibouri A.K.H., Wu J., Upreti S.R. 2015. Continuous ozonation of methylene blue in water. Journal of Water Process Engineering, 8, 142-150.

6. Almaamary, E.A.S., Abdullah, S.R.S., Hasan, H.A.,
Rahim, R.A.A., Idris, M. 2017. Treatment of methylene blue in wastewater using Scirpus grossus. Malaysian Journal of Analytical Sciences, 21(1), 182-187.

7. Basava Rao V.V., Ram Mohan Rao, S. 2006. Adsorption studies on treatment of textile dyeing industrial effluent by flyash. Chemical Engineering Journal, 116(1), 77-84.

8. Bayomie, O.S., Kandeel, H., Shoeib, T., Yang, H., Youseff, N., El-Sayed, M.H. 202. Novel approach for effective removal of methylene blue dye from water using fava bean peel waste. Sci Rep 10, 7824.

9. Bi Z., He B.B. 2013. Characterization of microalgae for the purpose of biofuel production. Transactions of the ASABE (American Society of Agricultural and Biological Engineers, 56(4), 1529-1539.

10. Bouatay, F., Dridi-Dhaouadi, S., Drira, N., Mhenni, M.F. 2016. Application of modified clays as an adsorbent for the removal of Basic Red 46 and Reactive Yellow 181 from aqueous solution. Desalination and Water Treatment, 57, 13561-13572.

11. Collin S.M.A., Wan G.J., Ashri M., Wan B. 2015. Preparation and characterization of activated carbon from Typha orientalis leaves. International Journal of Industrial Chemistry, 6, 9-21.

12. De Mattos F.C.G., Da J.A., Do A.B., De Mac Edo J.L., Dias J.A., Dias S.C.L., Ghesti G.F. 2012. Lewis $\mathrm{acid} /$ surfactant rare earth trisdodecylsulfate catalysts for biodiesel production from waste cooking oil. Applied Catalysis A: General, 423-424, 1-6.

13. Geçgel U., Özcan G., Gürpınar G.C. 2013. Removal of methylene blue from aqueous solution by activated carbon prepared from pea shells (Pisum sativum). Journal of Chemistry, 2013, 1-9

14. Golder A.K., Hridaya N., Samanta A.N., Ray S. 2005. Electrocoagulation of methylene blue and eosin yellowish using mild steel electrodes. Journal 
of Hazardous Materials, 127, 134-140.

15. Gupta V.K., Suhas. 2009. Application of low-cost adsorbents for dye removal - A review. Journal of Environmental Management, 90(8), 2313-2342.

16. Gupta, V.K., Ali, S.I., Saini, V.K. 2004. Removal of rhodamine B, fast green, and methylene blue from wastewater using red mud, an aluminum industry waste. Industrial \& Engineering Chemistry Research, 43, 1740-1747.

17. Heidari A., Younesi H., Rashidi A., Ghoreyshi A.A. 2014. Evaluation of CO2 adsorption with eucalyptus wood based activated carbon modified by ammonia solution through heat treatment. Chemical Engineering Journal, 254, 503-513.

18. Hesas, R.H., Arami-Niya A., Wan Daud, W.M.A., Sahu J.N. 2013. Preparation and characterization of activated carbon from apple waste by microwaveassisted phosphoric acid activation: Application in methylene blue adsorption. BioResources, 8, 2950-2966.

19. Imron, M.F., Kurniawan, S.B., Soegianto, A., Wahyudianto, F.E. 2019. Phytoremediation of methylene blue using duckweed (Lemna minor). Heliyon 5, e02206.

20. Jawad A.H., Abdulhameed A.S., Mastuli M.S. 2020. Acid-factionalized biomass material for methylene blue dye removal: a comprehensive adsorption and mechanism study. Journal of Taibah University for Science, 14, 305-313.

21. Jawad A.H., Razuan R., Appaturi J.N., Wilson L.D. 2019. Adsorption and mechanism study for methylene blue dye removal with carbonized watermelon (Citrullus lanatus) rind prepared via one-step liquid phase $\mathrm{H} 2 \mathrm{SO} 4$ activation. Surfaces and Interfaces, $16,76-84$

22. Khodaie M., Ghasemi N., Moradi B., Rahimi M. 2013. Removal of methylene blue from wastewater by adsorption onto $\mathrm{ZnCl} 2$ activated corn husk carbon equilibrium studies. Journal of Chemistry, 2013, 1-6.

23. Kumar, D.P., Mohamed, A.R., Bhatia, S. 2002. Wastewater treatment using photocatalysis: Destruction of methylene blue dye from wastewater streams. Jurnal Kejuruteraan 14, 17-30.
24. Liu L., He D., Pan F., Huang R., Lin H., Zhang X. 2020. Comparative study on treatment of methylene blue dye wastewater by different internal electrolysis systems and COD removal kinetics, thermodynamics and mechanism. Chemosphere, 238, 124671.

25. Mahmoud M.S., Farah J.Y., Farrag T.E. 2013. Enhanced removal of Methylene Blue by electrocoagulation using iron electrodes. Egyptian Journal of Petroleum, 22, 211-216.

26. Muhamad, M.H., Sheikh Abdullah, S.R., Abu Hasan, H., Abd. Rahim, R.A. 2015. Comparison of the efficiencies of attached- versus suspendedgrowth SBR systems in the treatment of recycled paper mill wastewater. Journal of Environmental Management, 163, 115-124.

27. Pathania D., Sharma S., Singh P. 2017. Removal of methylene blue by adsorption onto activated carbon developed from Ficus carica bast. Arabian Journal of Chemistry, 10, S1445-S1451.

28. Somsesta N., Sricharoenchaikul V., Aht-Ong D. 2020. Adsorption removal of methylene blue onto activated carbon/cellulose biocomposite films: Equilibrium and kinetic studies. Materials Chemistry and Physics, 24015, 122221.

29. Sulizi, P.A.S., Mobarak, N.N. 2020. Kinetic studies and absorption isothermal of methylene blue by using N,O-carboxymethyl chitosan. Malaysian Journal of Analytical Sciences, 24(1), 21-32.

30. Tangahu, B.V., Ningsih, D.A., Kurniawan, S.B., Imron, M.F. 2019. Study of BOD and COD removal in batik wastewater using Scirpus grossus and Iris pseudacorus with intermittent exposure system. Journal of Ecological Engineering, 20(5), 130-134.

31. Uddin M.T., Rahman M.A., Rukanuzzaman M., Islam, M.A. 2017. A potential low cost adsorbent for the removal of cationic dyes from aqueous solutions. Applied Water Science, 7, 2831-2842.

32. Zhang S., Wang D., Zhou L., Zhang X., Fan P., Quan X. 2013. Intensified internal electrolysis for degradation of methylene blue as model compound induced by a novel hybrid material: Multi-walled carbon nanotubes immobilized on zero-valent iron plates (Fe0-CNTs). Chemical Engineering Journal, 2171, 99-107. 